\title{
Cognitive dysfunctions and white matter lesions in patients with bipolar disorder in remission.
}

Citation for published version (APA):

Krabbendam, A. C., Honig, A., Wiersma, J., Vuurman, E. F. P. M., Hofman, P. A. M., Derix, M. M. A., Nolen, W. A., \& Jolles, J. (2000). Cognitive dysfunctions and white matter lesions in patients with bipolar disorder in remission. Acta Psychiatrica Scandinavica, 101(4), 274-280. https://doi.org/10.1034/j.16000447.2000.101004274.x

Document status and date:

Published: 01/01/2000

DOI:

10.1034/j.1600-0447.2000.101004274.x

Document Version:

Publisher's PDF, also known as Version of record

\section{Please check the document version of this publication:}

- A submitted manuscript is the version of the article upon submission and before peer-review. There can be important differences between the submitted version and the official published version of record.

People interested in the research are advised to contact the author for the final version of the publication, or visit the DOI to the publisher's website.

- The final author version and the galley proof are versions of the publication after peer review.

- The final published version features the final layout of the paper including the volume, issue and page numbers.

Link to publication

\footnotetext{
General rights rights.

- You may freely distribute the URL identifying the publication in the public portal. please follow below link for the End User Agreement:

www.umlib.nl/taverne-license

Take down policy

If you believe that this document breaches copyright please contact us at:

repository@maastrichtuniversity.nl

providing details and we will investigate your claim.
}

Copyright and moral rights for the publications made accessible in the public portal are retained by the authors and/or other copyright owners and it is a condition of accessing publications that users recognise and abide by the legal requirements associated with these

- Users may download and print one copy of any publication from the public portal for the purpose of private study or research.

- You may not further distribute the material or use it for any profit-making activity or commercial gain

If the publication is distributed under the terms of Article $25 \mathrm{fa}$ of the Dutch Copyright Act, indicated by the "Taverne" license above, 


\section{Cognitive dysfunctions and white matter lesions in patients with bipolar disorder in remission}

Krabbendam L, Honig A, Wiersma J, Vuurman EFPM, Hofman PAM, Derix MMA, Nolen WA, Jolles J. Cognitive dysfunctions and white matter lesions in patients with bipolar disorder in remission.

Acta Psychiatr Scand 2000: 101: 274-280. (C) Munksgaard 2000.

Objective: To compare cognitive functioning in relation to white matter lesions in bipolar disorder in remission and schizophrenia.

Method: Cognitive performance and the occurrence of white matter lesions on MRI images of the brain were assessed in 22 patients with bipolar disorder in remission, 22 patients with schizophrenia and 22 healthy volunteers.

Results: Performance of tests of memory, speed and cognitive flexibility was significantly impaired in both patient groups. The frequency of white matter lesions did not differ significantly between the three groups. No differences in cognitive performance were found between patients with white matter lesions and patients without such lesions.

Conclusion: White matter lesions apparently do not underlie cognitive deficits that are found in patients with bipolar disorder in remission and in patients with schizophrenia.

\author{
L. Krabbendam', A. Honig', \\ J. Wiersma', E. F. P. M. Vuurman', \\ P. A. M. Hofman', M. M. A. Derix', \\ W. A. Nolen ${ }^{3}$, J. Jolles' \\ ${ }^{1}$ Department of Psychiatry and Neuropsychology, \\ Maastricht University and University Hospital \\ Maastricht, The Netherlands, ${ }^{2}$ Department of \\ Radiology, University Hospital Maastricht, \\ The Netherlands and ${ }^{3}$ H.C. Rümke Group and \\ University Medical Centre Utrecht, The Netherlands
}

Key words: affective disorders; schizophrenia; cognition; magnetic resonance imaging

L. Krabbendam, Department of Psychiatry and Neuropsychology, Maastricht University, P0 Box 88, 6200 AB Maastricht, the Netherlands

Accepted for publication October 4, 1999

\section{Introduction}

Several authors have questioned the view that mood disorders and schizophrenia are distinct diseases $(1,2)$. Instead, on the basis of family studies, brain morphology and the frequency of intermediate forms of illness (i.e. schizoaffective disorder), it has been suggested that they are part of a continuum of liability to psychosis. In line with this suggestion, some neuropsychological studies have reported similar patterns of cognitive deficit in bipolar disorder and schizophrenia $(3,4)$, although another study found no such pattern (5). However, in these studies patients with bipolar disorder were investigated in either the acute manic or acute depressed state, which makes the results difficult to interpret because these states could have affected cognitive function. Indeed, the traditional view holds that cognitive deficits in mood disorder are state-dependent, in contrast to the persistent deficits associated with schizophrenia $(6,7)$. Nevertheless, those few studies that have investigated patients with bipolar disorder in remission have suggested that some cognitive impairments may persist during clinical recovery $(8-10)$.

Cognitive dysfunction during recovery would be consistent with the recent finding of structural brain changes in patients with bipolar disorder (11). Magnetic resonance imaging (MRI) studies have shown that there is ventricular enlargement and an increased frequency of white matter lesions in patients with bipolar disorder compared to healthy controls $(12,13)$. One study found that white matter lesions were more severe in patients with bipolar disorder than in patients with schizophrenia (13), whereas another study found the reverse (14). The aetiology of white matter lesions is not clear, but they are possibly associated with cerebrovascular changes $(15,16)$. The increased occurrence of white matter lesions in bipolar disorder may underlie cognitive deficits observed during remission. Indeed, one study found that patients with bipolar disorder and white matter lesions had poorer cognitive function than did patients without lesions (12), but this was not confirmed in another study (13). 
The present study investigated cognitive functioning in relation to white matter lesions in patients with bipolar disorder who were in remission in comparison to both patients with schizophrenia and healthy controls. The neuropsychological assessment focused on memory, attention and speed of information processing, and cognitive flexibility, because impairments in these domains are often seen in mood disorder $(17,18)$ and schizophrenia $(19,20)$. Direct comparison of patients with bipolar disorder in remission and patients with schizophrenia will shed light on similarities and differences in the patterns of cognitive deficit in both disorders as well as on the nature of brain abnormalities that may underlie this deficit.

\section{Material and methods}

Subjects

Forty-five patients with bipolar disorder were screened initially. Seventeen patients were excluded on the basis of the exclusion criteria. Five patients withdrew because they found the study too timeconsuming and one patient dropped out due to a panic attack during MRI scanning. The study group consisted of 22 patients with bipolar disorder, 22 patients with schizophrenia and 22 healthy volunteers. The exclusion criteria for all three groups were diagnosis of schizoaffective disorder, older than 60 years, left-handedness, a history of cardiological or cerebrovascular disease, head injury that caused unconsciousness for more than $1 \mathrm{~h}$, diabetes mellitus, hypertension and substance abuse over the last 12 months. This information was obtained from a medical interview and the case records. The patients with bipolar disorder had to be in remission for at least 2 months (according to the DSM-IV criterion for full remission). Additional exclusion criteria for the control group were any history of psychiatric illness and use of psychoactive medication. Written informed consent was obtained from all participants.
Diagnoses were made by a psychiatrist according to DSM-IV criteria (21) and verified by means of the Structured Clinical Interview for DSM-IV Disorders (22) for patients with bipolar disorder and the Composite International Diagnostic Interview (23) for patients with schizophrenia. Twelve patients fulfilled criteria for bipolar I disorder (296.x) and 10 for bipolar II disorder (296.89). Twelve patients were diagnosed with bipolar disorder with psychotic features and 10 with bipolar disorder without psychotic features. The patients with bipolar disorder were recruited from the Department of Psychiatry of the Academic Hospital Maastricht and the H.C. Rümke Group in Utrecht (Stanley Foundation Bipolar Network). The patients with schizophrenia were recruited from the local psychiatric departments in the catchment area (RIAGG Maastricht and Psychomedical Center Vijverdal Maastricht). The control subjects were recruited via newspaper advertisements.

Participant characteristics are shown in Table 1. All patients were out-patients at the time of the assessment. The patients with bipolar disorder were matched with the control subjects on age, but as a group they were somewhat older than the patients with schizophrenia. The three groups were matched on educational level, which was measured on an 8 -point scale, ranging from primary school to university degree (24). All patients had a chronic course of their illness, as indicated by a mean number of depressive episodes of $6.2(\mathrm{SD}=5.1)$ and a mean number of manic or hypomanic episodes of $3.9(\mathrm{SD}=3.7)$ in the patients with bipolar disorder, and a mean number of years of illness duration of $13.4(\mathrm{SD}=6.3)$ in the patients with schizophrenia. Mean age at first episode was 32.2 years $(\mathrm{SD}=9.4)$ in the patients with bipolar disorder and 25.5 years $(\mathrm{SD}=7.5)$ in the patients with schizophrenia. Severity of symptomatology was assessed with the 17-item Hamilton Depression Rating Scale (25) and the Young Mania Rating Scale (26) in the patients with bipolar disorder and the Brief Psychiatric Rating Scale (27) in the patients with schizophrenia. Of the patients with bipolar disorder, 16 were using

Table 1. Means (standard deviations) and summary statistics of participant characteristics

\begin{tabular}{|c|c|c|c|c|c|}
\hline & $\begin{array}{l}\text { Bipolar } \\
(n=22)\end{array}$ & $\begin{array}{c}\text { Schizophrenia } \\
(n=22)\end{array}$ & $\begin{array}{l}\text { Normal } \\
(n=22)\end{array}$ & $F(2,63)$ & $P$ \\
\hline Age & $47.7(8.3)$ & $39.6(6.6)$ & $41.4(11.3)$ & 4.96 & $0.01^{*}$ \\
\hline $\operatorname{Sex}\langle M / F\rangle$ & $5 / 17$ & $12 / 10$ & $10 / 12$ & 4.89 & $0.09^{a}$ \\
\hline Level of education & $4.0\{2.2\}$ & $4.0(1.7)$ & $4.1(1.5)$ & 0.03 & 0.97 \\
\hline I0 score & $102.4(21.4)$ & $94.6(13.0)$ & $114.2(13.0)$ & 8.13 & $0.00^{* *}$ \\
\hline Hamilton Depression Rating Scale 3.4 (3.0) & $3.4(3.0)$ & $N A^{b}$ & NA & & \\
\hline Young Mania Rating Scale & $0.77(1.5)$ & NA & NA & & \\
\hline Brief Psychiatric Rating Scale & NA & $45.3(10.3)$ & NA & & \\
\hline
\end{tabular}

${ }^{a}$ Chi-square test. ${ }^{b} \mathrm{NA}$ : not assessed. ${ }^{*}$ Significant difference between bipolar and schizophrenic subjects (Tukey-HSD test, $P<0.05$ ). ${ }^{* *}$ Significant difference between schizophrenic and control subjects (Tukey-HSD test, $P<0.05$ ). 
lithium and six carbamazepine. Six patients were also using antidepressants and two were using benzodiazepines. Of the patients with schizophrenia, all but one were using antipsychotic medication (mean dose in chlorpromazine equivalents $=329$, $S D=214$ ), four patients were also using anticholinergic medication and five were using antidepressants.

\section{Neuropsychological assessment}

The neuropsychological assessment was directed at the following cognitive domains: recall from shortterm and long-term memory, attention and speed of information processing and cognitive flexibility. The tests were administered to all subjects, except one patient from the bipolar group.

The Auditory Verbal Learning Task (AVLT) (28) was used to evaluate retrieval from memory as well as recognition. As measures of attention and speed of information processing we used the reading and colour-naming tasks of the Stroop Color-Word Test (SCWT) (29), the number-tracking and lettertracking tasks of the Concept Shifting Test (CST) (30), which is a modified version of the Trailmaking Test (31), and the Letter Digit Substitution Test (LDST), which is a modified version of the Symbol Digit Modalities Test (32). To assess cognitive flexibility we used the interference task of the SCWT, the number/letter-shifting task of the CST and Word Fluency (33). To obtain a measure of general intelligence we used the shortened form of a widely used Dutch intelligence test, the Groningen Intelligence Test (GIT) (34). This test yields results that are comparable to the Wechsler Adult Intelligence Scale. Three subtests have proved to be a good approximation of fullscale IQ (34).

MR

MRI scans were made with a 1.5-Tesla scanner (Gyroscan ACS-II, Philips). Transverse spin-echo sequences (T2-weighted, TR $3000 \mathrm{~ms}$, TE 23$120 \mathrm{~ms}$, TF 12, NSA 2, FOV $230 \mathrm{~mm}$, voxel dimensions $0.9 \mathrm{~mm} \times 1.2 \mathrm{~mm}$ ) were used. Twentyfour slices were obtained with a thickness of $5 \mathrm{~mm}$ and a $0.5 \mathrm{~mm}$ gap between slices. All images were blindly rated by an experienced neuroradiologist (P.H.). Periventricular lesions in the caps and the bands were rated using a semiquantitative severity rating scale from 0 to 3 . Deep white matter lesions were rated as small (less than $3 \mathrm{~mm}$ ), medium (between 4 and $10 \mathrm{~mm}$ ) or large lesions (more than $10 \mathrm{~mm}$ ). Care was taken to exclude small white matter lesions that are usually considered normal.

The MRI scans were recorded as part of a larger study $(n=300)$ into white matter lesions. Of this sample, a subset of 29 scans was measured twice.
For this subset, kappa values were calculated as a measure of concordance. For the small deep white matter lesions kappa was $0.55(95 \% \mathrm{CI}=0.37-0.74)$, for the medium lesions kappa was $0.74(95 \% \mathrm{CI}=$ $0.53-0.94$ ), for the large lesions kappa was 0.65 $(95 \% \mathrm{CI}=-0.15-1.00)$, for the periventricular frontal caps lesions kappa was $0.78 \quad(95 \% \mathrm{CI}=$ 0.62-0.94), for the occipital caps kappa was 0.66 $(95 \% \mathrm{CI}=0.49-0.84)$ and for the bands kappa was $0.83(95 \% \mathrm{CI}=0.70-0.96)$, indicating sufficient to good concordance for all parameters.

\section{Statistical analysis}

All statistical analyses were performed using SPSS for Macintosh (version 6.1). Cognitive task performance in the bipolar group, the schizophrenic group and the control group was analysed in a between-group design using multivariate analysis of variance (MANOVA) with age and sex as covariates. Significant results were analysed further using 1-way analysis of variance with the Tukey multiple comparison procedure. $t$-Tests for independent samples were used to examine differences in cognitive performance between patients with bipolar I or bipolar II disorder, between patients with or without psychotic features and between patients using lithium or carbamazepine. Because of the non-normal distribution, group differences in the presence and the number of white matter lesions were analysed non-parametrically, using the chisquare test and the Kruskal-Wallis test, respectively. A series of $t$-tests for independent samples was used to analyse cognitive performance in the subjects with white matter lesions compared to those without lesions. Correlations between frequency of white matter lesions and age were computed for each group separately, using Spearman rank order correlation coefficients.

\section{Results}

The results of the MANOVA showed a significant main effect of group $(F(26,96)=2.01, P=0.008$, Pillai's test). Pairwise analysis of the significant univariate group differences indicated that the patients with schizophrenia performed significantly worse than the control subjects on all measures (see Table 2). The patients with bipolar disorder had a significantly poorer performance than the control subjects on AVLT short-term and long-term recall, on CST letter-tracking and number/letter-shifting and on the LDST. Three patients with bipolar disorder and one patient with schizophrenia had an IQ score below 75. However, post hoc analyses showed that these subjects did not contribute disproportionately to the findings. 
Table 2. Means (standard deviations) and F-test statistics of cognitive performance for the bipolar, schizophrenic and control groups

\begin{tabular}{|c|c|c|c|c|c|}
\hline & $\begin{array}{l}\text { Bipolar } \\
(n=21)\end{array}$ & $\begin{array}{l}\text { Schizophrenia } \\
\qquad(n=22)\end{array}$ & $\begin{array}{l}\text { Normal } \\
(n=22)\end{array}$ & $F(2,61)$ & $P$ \\
\hline \multicolumn{6}{|l|}{ Auditory Verbal Learning Test } \\
\hline Immediate recall & $43.1(10.2)$ & $40.9(11.9)$ & $52.3(9.3)$ & 7.99 & $0.001^{a, b}$ \\
\hline Delayed recall & $8.3(3.5)$ & $8.4(2.6)$ & $11.3(2.9)$ & 6.88 & $0.002^{a, b}$ \\
\hline Recognition & $14.0(1.6)$ & $13.6(1.9)$ & $14.6(0.6)$ & 2.97 & 0.059 \\
\hline \multicolumn{6}{|l|}{ Stroop Color Word Test } \\
\hline Colour-reading & $47.2(9.4)$ & $53.7(16.1)$ & $42.4(6.1)$ & 5.45 & $0.007^{b}$ \\
\hline Colour-naming & $64.3(13.5)$ & $73.3\langle 19.1\rangle$ & $56.3(11.3)$ & 7.08 & $0.002^{b}$ \\
\hline Interference & $107.7(34.1)$ & $122.2(39.5)$ & $88.4(22.8)$ & 5.89 & $0.005^{b}$ \\
\hline \multicolumn{6}{|l|}{ Concept Shifting Test } \\
\hline Number-tracking & $22.0(7.9)$ & $24.5(5.3)$ & $18.2(6.4)$ & 4.98 & $0.010^{b}$ \\
\hline Letter-tracking & $28.5(9.8)$ & $27.4(6.4)$ & $20.9(5.2)$ & 6.67 & $0.002^{a, b}$ \\
\hline Number/letter-switching & $40.1(19.0)$ & $39.5(15.2)$ & $25.1(6.5)$ & 7.45 & $0.001^{a b}$ \\
\hline Letter Digit Substitution Test & $43.9(11.5)$ & $40.7(10.1)$ & $54.9(7.8)$ & 12.36 & $0.000^{a, b}$ \\
\hline Fluency & $21.5(5.8)$ & $19.8(5.2)$ & $24.9(6.7)$ & 4.18 & $0.020^{b}$ \\
\hline
\end{tabular}

${ }^{a}$ Significant difference between bipolar and control group (Tukey-HSD test; $P<0.05$ ). ${ }^{b}$ Significant difference between schizophrenic and control group (Tukey-HSD test; $P<0.05)$.

$t$-Tests for independent groups showed that the cognitive performance of the 16 patients using lithium was not different from that of the six patients using carbamazepine. No differences in cognitive performance were found between the patients with bipolar I or bipolar II disorder or between the patients with or without psychotic features. There were no significant correlations between cognitive performance and clinical variables (number of episodes and symptomatology ratings).

Table 3 shows the frequency of the white matter lesions per group. There were no significant differences between the groups in the occurrence of periventricular and deep white matter lesions, nor were there significant differences between the three groups in the severity of the periventricular lesions in the bands $\left(\chi^{2}=4.11, P=0.13\right)$ or the caps $\left(\chi^{2}=1.78, P=0.41\right)$. Of the subjects with deep white matter lesions, the patients with bipolar disorder had a mean of 5.2 lesions, the patients with schizophrenia 4.0 lesions and the healthy subjects 3.6 lesions $\left(\chi^{2}=0.13, P=0.94\right)$. In the patients with bipolar disorder, $71 \%$ of the deep white matter lesions was located in the frontal lobes, in the patients with schizophrenia this percentage was $91 \%$

Table 3. The frequency (\%) of white matter lesions in each group

\begin{tabular}{lccccc}
\hline & $\begin{array}{c}\text { Bipolar } \\
(n=22)\end{array}$ & $\begin{array}{c}\text { Schizophrenia } \\
(n=22)\end{array}$ & $\begin{array}{c}\text { Control } \\
(n=22)\end{array}$ & $\chi^{2}$ & $P$ \\
\hline $\begin{array}{l}\text { Periventricular } \\
\text { Bands }\end{array}$ & $13.6 \%$ & $18.2 \%$ & 0 & 4.15 & 0.13 \\
$\quad$ Caps & $13.6 \%$ & $18.2 \%$ & $4.5 \%$ & 1.99 & 0.37 \\
$\begin{array}{l}\text { Deep white matter } \\
\text { Small }\end{array}$ & $63.6 \%$ & $40.9 \%$ & $50 \%$ & 2.31 & 0.32 \\
$\quad$ Medium & $27.3 \%$ & $13.6 \%$ & $22.7 \%$ & 1.27 & 0.53 \\
$\quad$ Large & 0 & 0 & 0 & - & - \\
\hline
\end{tabular}

and in the healthy subjects this percentage was $93 \%$. No differences were found between bipolar disorder type I and type II, or between bipolar disorder with and without psychotic features, or between male and female subjects in any of the groups. No differences in the number of white matter lesions were found between the left and the right hemispheres in any of the three groups. The cognitive performance of the subjects with deep white matter lesions did not differ from that of the subjects without lesions in any of the three groups. Post hoc power estimations indicated that the power of these analyses was between 0.15 and 0.46 . The number of subjects with periventricular lesions was considered too small (three in the bipolar and four in the schizophrenic group) to examine the possible relationship between lesions and cognitive performance deficits in these subjects. The number of white matter lesions was not correlated with age.

\section{Discussion}

\section{Cognitive functions}

The most salient finding was that out-patients with bipolar disorder in remission have a rather diffuse pattern of cognitive deficits, similar to patients with schizophrenia. In both groups the cognitive deficits involve memory, speed of information processing and cognitive flexibility. However, the performance deficit was generally less severe than that of the patients with schizophrenia. Although there were differences between the two groups with regard to age and sex it is unlikely that these differences can explain the findings, since we corrected for these variables in the analysis. In contrast to the results of the study by Albus et al. (35), the presence of the 
cognitive impairment in bipolar disorder was not associated with the presence of psychotic features.

The groups were matched on educational level. However it is possible that, in particular, the patients with schizophrenia had higher potential abilities than the control group, as in schizophrenia the onset of illness might interfere with the educational career.

All patients with bipolar disorder were taking psychoactive medication at the time of the assessment, which may have influenced cognitive performance. However, for ethical reasons we considered it not appropriate to discontinue medication for the time of the study. Most of the patients with bipolar disorder were taking lithium, which in a recent meta-analysis of studies was found to have a negative effect on memory and speed of information processing (36). The evidence for negative sideeffects of carbamazepine on cognitive functioning is inconsistent (37-39). In the present study, there were no differences in cognitive performance between patients taking lithium and those taking carbamazepine.

Another point of consideration is that we did not include subjects on the basis of either consecutive admissions or random selection. It is possible that the results are somewhat biased, because subjects who experience cognitive problems might be more willing to participate.

\section{White matter lesions}

There were no statistically significant differences between the three groups in the occurrence and severity of white matter lesions and in the mean number of lesions per subject. Of interest is the finding that none of the healthy subjects had periventricular lesions in the bands whereas a minority of patients in the two patient groups did, but this finding should be replicated. Similar to the study by Dupont et al. (12), most deep white matter lesions were located in the frontal lobes.

The bipolar patients included in the present study were fairly young and all had their first episode at a relatively young age. However, since they were matched for age with the control subjects, the young age cannot explain the lack of differences between the groups. Further, there is evidence for an association between high frequency of white matter lesions and late onset of affective disorder, but this effect appears to be specific to unipolar disorder (11).

Our results contrast with those of some previous studies $(13,40)$ but are consistent with those of other studies $(41,42)$. These differences may be due to the different methods used. For example, the relatively low frequency of deep white matter lesions in healthy controls in the study of Swayze et al. (13) (4.3\%) compared to the present study (50.0\% for small lesions and $22.7 \%$ for medium lesions) and other studies $(14,43)$ may be due to the use of eight cuts of a thickness $1 \mathrm{~cm}$ in the study by Swayze et al. compared to 24 cuts of $5 \mathrm{~mm}$ in the present study.

The view that white matter lesions are unlikely in young healthy people may be influenced by a bias in the selection of control subjects in several studies (e.g. medical staff). It has been suggested that white matter lesions are more likely to occur in people from a less privileged background (44). This might explain the relatively high frequency of white matter lesions in our study, in which we matched subjects for level of education. This is, however, a tentative explanation which needs further investigation.

\section{Cognitive deficits and white matter lesions}

No relationship was found between cognitive deficits and white matter lesions in the two patient groups. Furthermore, healthy subjects who were cognitively normal showed a similar frequency of white matter lesions. This supports previous suggestions that white matter lesions do not necessarily have a negative effect on cognitive function $(45,46)$, although severe white matter disease is probably associated with cognitive dysfunction (47). However, the estimated power of the present analyses indicate that the results must be tentatively interpreted. Indeed, some other studies did find a relation between white matter lesions and cognitive functioning $(48,49)$. In the present study, neuropsychological tests were used that have shown to be sensitive to cognitive deficits commonly associated with biolar disorder and schizophrenia. Future studies should investigate whether white matter lesions are associated with other cognitive functions, such as visuospatial and executive abilities.

This lack of a relationship suggests that some other brain abnormality underlies the observed cognitive deficits in bipolar disorder and schizophrenia. One explanation could be that schizophrenia and mood disorders are part of a continuum (1). Nasrallah has argued that bipolar disorder is characterized by structural brain abnormalities similar to those of schizophrenia, which in both disorders may have a neurodevelopmental origin (50). A second explanation for the cognitive deficits may be that they reflect longlasting changes in the brain which, as Post (51) has suggested, may occur in bipolar disorder following psychosocial stressors or episodes of mania or depression. A third possibility is that hypercortisolaemia, which occurs during episodes of mania 
or depression, leads to structural changes in the brain, thus explaining cognitive deficits in euthymic periods (52). The lack of an association between the number of episodes of mania or depression and cognitive deficits in the present study does not support this hypothesis; however, the number of episodes may be too crude a measure of illness severity.

Our findings indicate that euthymic patients with bipolar disorder have persistent cognitive deficits which involve several domains, as do the cognitive deficits seen in patients with schizophrenia. White matter lesions apparently do not underlie these deficits. Indeed, small white matter lesions do not appear to affect cognitive function, because these lesions were also seen in the cognitively normal control group.

\section{Acknowledgement}

Dr Nolen thanks the Ted and Vada Stanley Foundation for support.

\section{References}

1. Crow TJ. The continuum of psychosis and its genetic origins: the sixty-fifth Maudsley lecture. $\mathrm{Br} \mathrm{J}$ Psychiatry 1990:156:788-797.

2. TAYLOR MA. Are schizophrenia and affective disorder related? A selective literature review. Am J Psychiatry 1992;149:22-32.

3. Hoff Al, Shukla $S$, Aronson $T$ et al. Failure to differentiate bipolar disorder from schizophrenia on measures of neuropsychological function. Schizophr Res 1990:3:253-260.

4. Zihl J, Gron G, Brunnauer A. Cognitive deficits in schizophrenia and affective disorders: evidence for a final common pathway disorder. Acta Psychiatr Scand 1998; 97:351-357.

5. Goldberg TE, Gold JM, Greenberg $R$ et al. Contrasts between patients with affective disorders and patients with schizophrenia on a neuropsychological test battery. Am J Psychiatry 1993;150:1355-1362.

6. Bulbena A, Berrios GE. Cognitive function in the affective disorders: a prospective study. Psychopathology 1993;26: 6-12.

7. Kraepelin E. Dementia praecox and paraphrenia. Edinburgh: Livingstone, 1913.

8. Coffman JA, Bornstein RA, Olson SC, Schwarzkopf SB, NaSrallah HA. Cognitive impairment and cerebral structure by MRI in bipolar disorder. Biol Psychiatry 1990; 27:1 188-1196.

9. Morice R. Cognitive inflexibility and pre-frontal dysfunction in schizophrenia and mania. Br J Psychiatry 1990; 157:50-54

10. Van Gorp WG, Altshuler L, Theberge DC, Wilkins J, Dixon W. Cognitive impairment in euthymic bipolar patients with and without prior alcohol dependence. A preliminary study. Arch Gen Psychiatry 1998;55:41-46.

11. VIDEBECH P. MRI findings in patients with affective disorder: a meta-analysis. Acta Psychiatr Scand 1997;96: 157-168.

12. Dupont RM, Jernigan TL, Butters $\mathbf{N}$ et al. Subcortical abnormalities detected in bipolar affective disorder using magnetic resonance imaging. Clinical and neuropsychological significance. Arch Gen Psychiatry 1990;47:55-59.

13. Swayze VW, Andreasen NC, Alliger RJ, Ehrhardt JC, YuH WT. Structural brain abnormalities in bipolar affective disorder. Ventricular enlargement and focal signal hyperintensities. Arch Gen Psychiatry 1990;47:1054-1059.

14. Persaud R, Russow H, Harvey I et al. Focal signal hyperintensities in schizophrenia. Schizophr Res 1997;27: $55-64$.

15. Awad IA, Spetzler RF, Hodak JA, Awad CA, Carey R. Incidental subcortical lesions identified on magnetic resonance imaging in the elderly: I. Correlation with age and cerebrovascular risk factors. Stroke 1986;17:1090-1097.

16. Schmidt R, Fazekas F, Offendacher $\mathrm{H}$ et al. Magnetic resonance imaging white matter lesions and cognitive impairment in hypertensive individuals. Arch Neurol 1991;48:417-420.

17. Derix MMA, Jolles J. Neuropsychological abnormalities in depression: relation between brain and behaviour. In: Honig A, VAN PraAg HM, ed. Depression: neurobiological, psychopathological and therapeutic advances. Chichester: Wiley, 1997:109-126.

18. KING DA, CaINe ED. Cognitive impairment and major depression: beyond the pseudodementia syndrome. In: Grant I, Adams KM, eds. Neuropsychological assessment of neuropsychiatric disorders, 2nd edn. Oxford: Oxford University Press, 1996:200-217.

19. Gourovitch ML, Goldberg TE. Cognitive deficits in schizophrenia: attention, executive functions, memory and language processing. In: Pantelis C, Nelson HE, Barnes TRE, eds. Schizophrenia: a neuropsychological perspective. Chichester: Wiley, 1996:71-86.

20. Schatz J. Cognitive processing efficiency in schizophrenia: generalized vs domain specific deficits. Schizophr Res 1998; 30:41-49.

21. American Psychiatric Association. Diagnostic and statistical manual of mental disorders, 4th edn. Washington, DC: American Psychiatric Press, 1994.

22. First MB, Spitzer RL, Williams JBW, Gibbon M. Structured Clinical Interview for DSM-IV (SCID). Washington, DC: American Psychiatric Association, 1997.

23. World Health Organization. Composite International Diagnostic Interview (CIDI); Version 1.1. Geneva 1993.

24. DE BIE SE. Standaardvragen 1987: voorstellen voor uniformering van vraagstellingen naar achtergrondkenmerken en interviews [Standard questions 1987: proposal for uniformization of questions regarding background variables and interviews], 2nd edn. Leiden: Leiden University Press, 1987.

25. Hamilton M. A rating scale for depression. J Neurol Neurosurg Psychiatry 1960;23:56-62.

26. Young RC, Biggs JT, Ziegler VE, Meyer DA. A rating scale for mania: reliability, validity, and sensitivity. Br J Psychiatry 1978;133:429-435.

27. Overall JE, Gorham DE. The brief psychiatric rating scale. Psychol Rep 1962;10:799-812.

28. BRAND N, Jolles J. Learning and retrieval rates of words presented auditorily and visually. J Gen Psychol 1985;112: 201-210.

29. Stroop JR. Studies of interference in serial verbal reactions. J Exp Psychol 1935;18:643-662.

30. Houx PJ, VReEling FW, Jolles J. Age-associated cognitive decline is related to biological life-events. In: IQBAL $\mathrm{K}$, MCLachlan DRC, Winblad B, Wisniewski HM, eds. Alzheimer's disease: basic mechanisms, diagnosis and therapeutic strategies. Chichester: Wiley, 1991:353-359.

31. Reitan RM. Validity of the Trail Making Test as an 
Krabbendam et al.

indication of organic brain damage. Percept Motor Skills 1958;8:271-276.

32. Sмгтн A. The Symbol Digit Modalities Test: a neuropsychological test for economic screening of learning and other cerebral disorders. Learn Disord 1968;36:83-91.

33. LeZAK MD. Neuropsychological assessment, 3rd edn. New York, Oxford: Oxford University Press, 1995.

34. Luteijn F, van der Ploeg FAE. Handleiding Groninger Intelligentietest (GIT) [Manual Groningen Intelligence Test]. Lisse, The Netherlands: Swets \& Zeitlinger, 1983.

35. Albus M, Hubmann W, Wahlheim C, Sobizack N, Franz U, Moнr F. Contrasts in neuropsychological test profile between patients with first-episode schizophrenia and first-episode affective disorders. Acta Psychiatr Scand 1996;94:87-93.

36. Honig A, Arts BMG, Ponds RWHM, Riedel WJ. Lithium induced cognitive side-effects in bipolar disorder: a qualitative analysis and implications for daily practice. Int J Clin Psychopharmacol 1999;14:167-171.

37. Prevey ML, Delaney RC, Cramer Ja, Cattanach L, Collins JF, Matrson RH. Effects of valproate on cognitive functioning. Comparison with carbamazepine. Arch Neurol 1996;53:1008-1016.

38. Duncan JS, Shorvon SD, Trimble MR. Effects of removal of phenytoin, carbamazepine, and valproate on cognitive function. Epilepsia 1990;31:584-591.

39. Vermeulen J, Aldenkamp AP. Cognitive side-effects of chronic antiepileptic drug treatment: a review of 25 years of research. Epilepsy Res 1995;22:65-95.

40. Dupont RM, Butters N, Schafer K, Wilson T, Hesselink J, GiLlin JC. Diagnostic specificity of focal white matter abnormalities in bipolar and unipolar mood disorder. Biol Psychiatry 1995;38:482-486.

41. Brown FW, Lewine RJ, Hudgins PA, Risch SC. White matter hyperintensity signals in psychiatric and nonpsychiatric subjects. Am J Psychiatry 1992;149:620-625.
42. Strakowski SM, Woods BT, Tohen M, Wilson DR, Douglass AW, Stoll AL. MRI subcortical signal hyperintensities in mania at first hospitalization. Biol Psychiatry 1993;33:204-206.

43. Bartzokis G, Garber HJ, Griswold VJ, Oldendorf WH, Mintz J, Marder $S$. $T_{2}$ hyperintense foci on magnetic resonance images of schizophrenic patients and controls. Psychiatr Res Neuroimag 1991;40:239-245.

44. Haryey I, Ron M, du Boulay G, Murray R, Lewis S. White matter abnormalities on magnetic resonance imaging in bipolar patients. Arch Gen Psychiatry 1990;47:1172-1173.

45. Tupler la, Coffey CE, Logue PE, Diang WT, Fagan SM. Neuropsychological importance of subcortical white matter hyperintensity. Arch Neurol 1992;49:1248-1252.

46. Fein G, Van Dycke C, Davenport L et al. Preservation of normal cognitive functioning in elderly subjects with extensive white-matter lesions of long duration. Arch Gen Psychiatry 1990;47:220-223.

47. Boone KB, Miller BL, Lesser IM et al. Neuropsychological correlates of white-matter lesions in healthy elderly subjects: a threshold effect. Arch Neurol 1992;49:549-554.

48. Fazekas F. Magnetic resonance signal abnormalities in asymptomatic individuals: their incidence and functional correlates. Eur Neurol 1989;29:164-168.

49. DeCarli C, Murphy DG, Tranh M et al. The effect of white matter hyperintensity volume on brain structure, cognitive performance, and cerebral metabolism of glucose in 51 healthy adults. Neurology 1995;45;2077-2084.

50. NASRALlah HA. Neurodevelopmental aspects of bipolar affective disorder. Biol Psychiatry 1991;29:1-2.

51. Post RM. Transduction of psychosocial stress into the neurobiology of recurrent affective disorder. Am J Psychiatry 1992;149:999-1010.

52. Altshuler LL. Bipolar disorder: are repeated episodes associated with neuroanatomic and cognitive changes? Biol Psychiatry 1993;33:563-565. 